\title{
Association of Serum C-reactive Protein in Preeclampsia and its Effect on Fetal Birth Weight - A Case Control Study
}

\author{
SHAHANAJ SHARMIN ${ }^{1}$, SHAHANARA CHY. ${ }^{2}$, DIADRUL ALAM ${ }^{3}$, NASREEN BANU $^{4}$, \\ FAHMIDA RASHID ${ }^{5}$, SHANJIDA KABIR ${ }^{6}$
}

\begin{abstract}
:
Objective(s): The aim of this study was to evaluate the association of serum C-reactive protein (CRP) in preeclampsia (PE) and its effect on fetal birth weight.

Materials and methods: This case control study was conducted in Chittagong Medical College Hospital, Bangladesh, from July 2013 to June 2014. Study population was pregnant women of third trimester with preeclampsia (case group) and normal blood pressure (control group). The maternal serum C-reactive protein (CRP) levels were measured by immune turbidometric assay between 32 weeks to term. The women were divided into three groups: mild PE, severe $P E$ (according to ACOG criteria) and normal healthy group. The value of CRP and its correlation with birth weight was compared between groups.
\end{abstract}

Results: One hundred and fifty (150) pregnant women were analyzed. Among them 50 were case and 100 control. There was no difference between age of the patients of both groups. The mean systolic blood pressure was $148.40 \pm 12.35 \mathrm{~mm} \mathrm{Hg}$ in case and $122.15 \pm 6.44$ $\mathrm{mmHg}$ in control group. The mean diastolic blood pressure was $100.00 \pm 9.74 \mathrm{mmHg}$ in case and $74.05 \pm 5.97 \mathrm{mmHg}$ for the control. The systolic and diastolic blood pressure was significantly higher in preeclamptic group $(P<0.000)$. C-reactive protein was $10.28 \pm 7.25 \mathrm{mg} /$ $\mathrm{mL}$ in mild PE and $10.94 \pm 6.32 \mathrm{mg} / \mathrm{mL}$ in severe $P E$ and $3.45 \pm 1.71 \mathrm{mg} / \mathrm{mL}$ in normotensive group, which was significantly higher in case than control group $(P=0.000)$. Preeclamptic women delivered at a significantly shorter gestational age than normal pregnant women. Mean gestational age during delivery for the case group and control group was $39.02 \pm 1.6$ and 39.58 \pm 0.8 weeks respectively. Mean birth weight in PE $(2.52 \pm 0.42 \mathrm{~kg})$ was significantly lower than normal pregnancies $(2.88 \pm 0.29 \mathrm{~kg})$. The sensitivity and specificity of CRP were $68 \%$ and $98 \%$ respectively. Multiple regression analysis showed that there is a strong association between $C R P$ levels and $P E$ and birth weight.

Conclusion: This small study showed that in case group CRP was raised in $68 \%$ cases which is much higher in comparison to healthy control group where CRP was high only in $2 \%$ cases. High CRP has association with low birth weight. Therefore, CRP may be used as cost effective investigation to identify the risk of preeclampsia and its effect on fetal birth weight.

Keywords : Preeclampsia, C-reactive protein, Birth weight

Introduction:

Pre-eclampsia (PE) is a characteristic disorder of pregnancy and endothelial dysfunction is likely to have a pivotal role in its pathophysiology ${ }^{1}$. It is a complicated, multi-organ disease occurring in up to $6-8 \%$ of pregnancies, typically after 20 weeks of gestation in previously normotensive women ${ }^{1,2}$. The presentation is highly variable and the etiology is

1. Assistant Prof. Gynae \& Obs., BBMH, USTC, Chittagong

2. Head of Department, Gynae \& Obs., Chittagong Medical College, Chittagong

3. Head of Department, Paediatrics, BBMH, USTC, Chittagong

4. Associate Prof. Gynae \& Obs., Chittagong Medical College, Chittagong

5. Assistant Prof. Gynae \& Obs., Chittagong Medical College, Chittagong

6. Registrar, Gynae \& Obs., BBMH, USTC, Chittagong

Address of Correspondence: Dr. Shahanaj Sharmin, Assistant Prof. Gynae \& Obs., BBMH, USTC, Chittagong, Mobile No. 01747051592, E-mail: sharmin35cmc@gmail.com 
multifactorial ${ }^{3,4}$. It remains a major cause of maternal, fetal and neonatal morbidity and mortality contributing a significant health care economic burden ${ }^{5,6}$.

There is no national data about incidence of preeclampsia in our country. According to annual departmental statistics of Chittagong Medical College and Hospital (CMCH), 2013 the prevalence was $7.68 \%$. Most cases of preeclampsia are mild and $90 \%$ occur after 34 weeks gestation ${ }^{7}$. It can manifest as a maternal disorder only with an appropriate fetal growth, or it can present itself with intrauterine growth restriction (IUGR) of fetus ${ }^{8}$.

C-reactive protein (CRP) is sensitive and specific index of overall inflammatory activity in the body ${ }^{9}$. Its sensitivity is high but non specific in nature. CRP levels are elevated in healthy pregnant women compared with non-pregnant women, although to a lesser extent than that seen in $P E^{10}$.

Production of CRP is stimulated by the release of proinflammatory cytokines including interleukin-1, interleukin-6, and tumor necrosis factor-alpha. It has been shown that elevated levels of CRP during gestation have been linked to adverse pregnancy outcomes such as preeclampsia ${ }^{11,12}$ and intrauterine growth restriction 12. There is also a significant association of elevated serum CRP levels with increased risk of delivery before 37 weeks' gestation ${ }^{13}$.

As CRP is cost effective and can be estimated easily in laboratory, it is considered as a marker in antenatal care (ANC) to monitor or predict the PE and its progression of severity. Intensive monitoring would be done in patients with high CRP, which may help to assess the severity of PE.

In light of the research reports, we examined prospectively the association between maternal serum CRP levels and PE and risk of IUGR and subsequent preterm delivery among a cohort of singleton pregnant women.

\section{Materials and methods:}

This was a case control study carried out in the Department of Obstetrics and Gynecology, Chittagong Medical College Hospital ( $\mathrm{CMCH})$, Chittagong between July 2013 to June 2014. This study included 150 women with singleton pregnancy in between 32 weeks to term (100 normotensive as control group and 50 preeclamptic as case group).

\section{Inclusion Criteria:}

The selection criteria for control group were normal blood pressure throughout pregnancy and no proteinuria, and cases were (a) blood pressure 140/ $90 \mathrm{~mm}$ of $\mathrm{Hg}$ or more taken on two occasions, 6 hours apart after the gestational age of 20 weeks and (b) proteinuria.

\section{Exclusion criteria:}

Exclusion criteria for both control and cases were:

(a) History of hypertension and/or proteinuria prior to conception or before 20 weeks of gestation

(b) Premature rupture of membrane (PROM)

(c) Obesity

(d) Symptomatic infectious disease

(e) Auto immune disease

(f) Any medical diseases like diabetes mellitus, renal disease, thyroid disease

(g) Mistaken date

(h) Drug abuse

(i) History of receiving aspirin or any other medication known to interfere with inflammation

(j) Alcohol and cigarette smoking

\section{Clinical assessment:}

With all aseptic precaution $4 \mathrm{ml}$ venous blood was drawn from ante-cubital vein from convenient side by vacuum syringe. Blood was allowed to stand still for about 30 minutes to clot. Clot was then separated from the test tube by wooden stick and was centrifuged within 1 hour of collection at $2000 \mathrm{rpm}$ for 5 minutes. The separated serum was carefully drawn by micropipette and was stored in micro centrifuged tube at $-70^{\circ} \mathrm{C}$ until the analysis was done. Estimation of serum CRP concentration was done by liquid phase immuneprecipitation assay and turbulometry at $\mathrm{Pvt}$. laboratory, Chittagong. Cut off value for CRP was $5 \mathrm{mg} / \mathrm{l}$.

Random urine sample was selected in a clean test tube and analyzed for presence of protein by dipstick reagent strip.

According to the ACOG terminology committee for preeclampsia, mild $\mathrm{PE}$ defined as when blood pressure is $>140 / 90 \mathrm{~mm} \mathrm{Hg}$ but $<160 / 110 \mathrm{~mm} \mathrm{Hg}$ with proteinuria $>1$ on dip stick reagent strip and severe $\mathrm{PE}$ when $\mathrm{BP}>160 / 110 \mathrm{~mm} \mathrm{Hg}$ with proteinuria $>2$ on dip stick reagent. 


\section{Study flow chart}

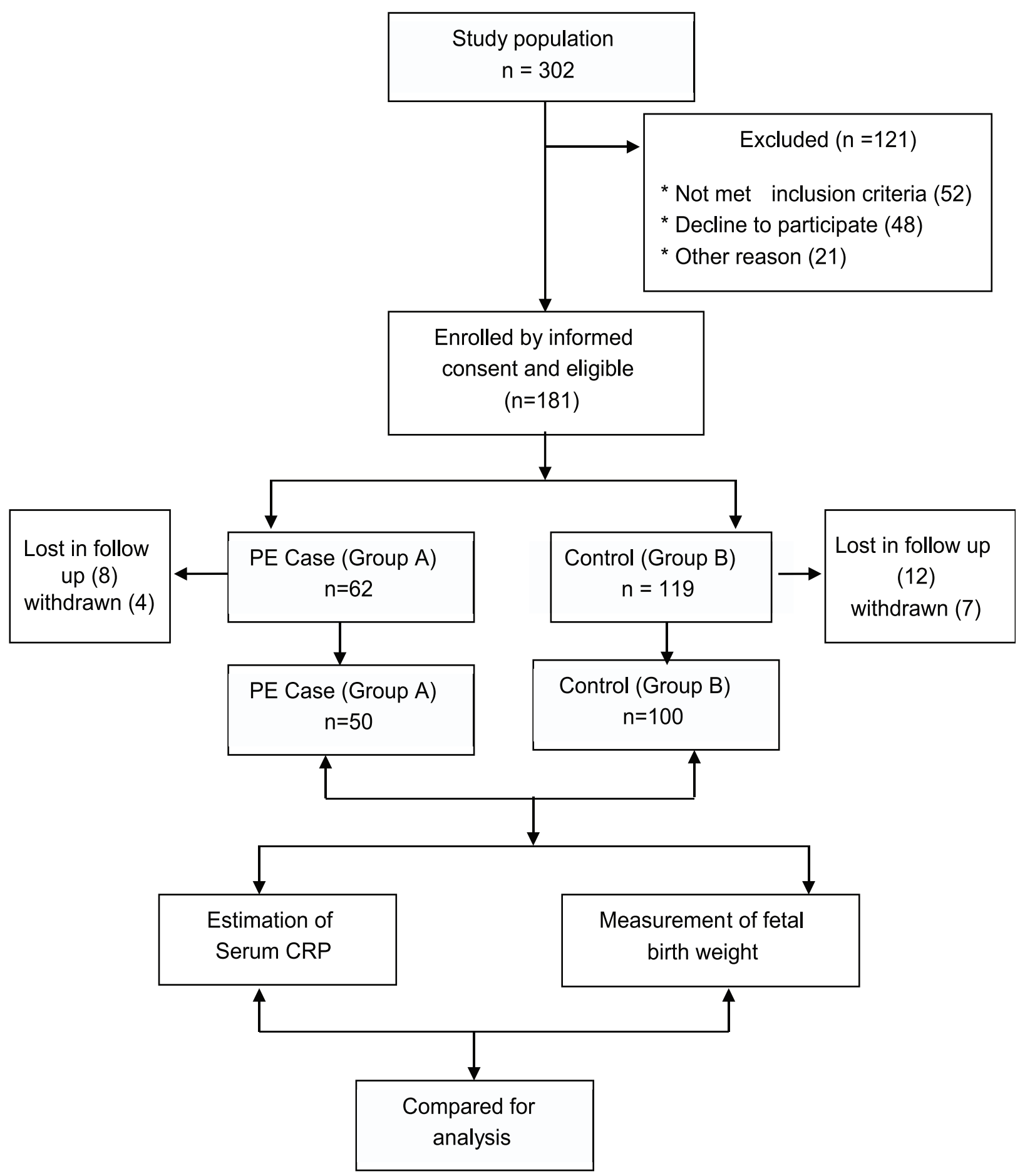

Gestational age was based on the first day of last menstrual period (LMP) who had regular cycle, Birth weight were collected from the delivery notes (normal values between $2.5-4 \mathrm{~kg}$ ), conducted in the Department of Obstetrics and Gynaecology at $\mathrm{CMCH}$.

\section{Ethical consideration:}

All cases and control group enrolled in this study were explained about the nature and purpose of the study, and only those who gave written informed consent included in the study. 


\section{Data processing:}

The obtained data plotted in a predesigned data collection sheet, and were compiled and appropriate analysis was done by using SPSS statistical package.

\section{Results:}

Table I showed characteristics of the study subjects. Mean age showed no significant difference between control (23.92 \pm 3.72 years) and study (24.58 \pm 4.05 years). Mean SBP was $122.15 \pm 6.44 \mathrm{mmHg}$ vs 148.40 $\pm 12.35 \mathrm{mmHg}$ and mean DBP was $74.05 \pm 5.97 \mathrm{mmHg}$ vs $100.00 \pm 9.74 \mathrm{mmHg}$ in control and study group respectively, which were higher in study group $(p<0.000)$.

Similarly mean gestational age at delivery was also significantly higher $(P<0.05)$ in study group (39.02 \pm 1.61 weeks) compared to control $(39.56+0.87$ weeks). Mean serum CRP level was significantly higher in study group $(10.48 \pm 6.93 \mathrm{mg} / \mathrm{ll})$ than control $(3.45 \pm 1.71 \mathrm{mg} / \mathrm{l})(\mathrm{P}=0.000)$. In control group CRP was normal in $98(98 \%)$ and raised in $2(2 \%)$ subjects; however in study group 16(32\%) had normal and 34 $(68 \%)$ raised CRP $(P<0.001)$. The mean birth weight of the neonate was $2.52 \pm 0.42 \mathrm{~kg}$ and $2.88 \pm 0.29 \mathrm{~kg}$ in study and control group respectively, which shows significant difference $(\mathrm{P}=0.000)$.

Table 2 showed that there was no significant difference of CRP level between mild (10.28 \pm 7.35$)$ and severe PE (10.94 \pm 6.32$)$, ( $p>0.05)$.

Table 3 showed validity test of CRP where sensitivity and specificity were $68.00 \%$ and $98.00 \%$ respectively. Clinical diagnosis of $\mathrm{PE}$ and normal pregnancy was taken as Gold Standard Test.

In the study group (Fig. 1) regression analysis showed that CRP had significant negative correlation with birth weight (birth weight: $r=-0.367 ; p<0.05$ )

Table-I

Characteristics of the women

\begin{tabular}{lccc}
\hline Variables & Case $(\mathrm{n}=50)$ Mean \pm SD & Control $(\mathrm{n}=100)$ Mean $\pm \mathrm{SD}$ & $\mathrm{P}$ value \\
\hline Age (years) & $24.58 \pm 4.05$ & $23.92 \pm 3.72$ & $0.322^{\mathrm{NS}}$ \\
Systolic blood pressure $(\mathrm{mm} \mathrm{Hg})$ & $148 \pm 12.35$ & $122.15 \pm 6.44$ & $0.000^{\mathrm{HS}}$ \\
Diastolic blood pressure $(\mathrm{mm} \mathrm{Hg})$ & $100 \pm 9.74$ & $74.05 \pm 5.97$ & $0.000^{\mathrm{HS}}$ \\
Gestational age at delivery $(\mathrm{wks})$ & $39.02 \pm 1.61$ & $39.56 \pm 0.87$ & $0.030^{\mathrm{S}}$ \\
CRP $(\mathrm{mg} / \mathrm{L})$ & $10.48 \pm 6.93$ & $3.45 \pm 1.71$ & \\
& $\mathrm{~N} \%$ & $\mathrm{~N} \%$ & $0.000^{\mathrm{HS}}$ \\
$\quad$ & $16(32 \%)$ & $98(98 \%)$ & \\
$\quad$ Normal & $34(68 \%)$ & $2(2 \%)$ & \\
Raised & Mean $\pm \mathrm{SD}$ & Mean $\pm \mathrm{SD}$ & $0.000^{\mathrm{HS}}$ \\
Weight of newborn $(\mathrm{Kg})$ & $2.52 \pm 0.42$ & $2.88 \pm 0.29$ & \\
\hline
\end{tabular}

Unpaired student's 't' test/chi square test, NS= Not Significant, $S=$ Significant, HS= Highly Significant.

Table-II

CRP according to types of PE among study group $(n=50)$

\begin{tabular}{lcl}
\hline Types of PE & Mean \pm SD & P value \\
\hline Mild & $10.28 \pm 7.25$ & $0.761^{\mathrm{NS}}$ \\
Severe & $10.94 \pm 62$ & \\
\hline
\end{tabular}

Unpaired students $\mathrm{t}$ test. NS= Not Significant

Regarding validity analysis, sensitivity of CRP was found $68.00 \%$ whereas specificity of CRP $98 \%$. Clinical Diagnosis of PE and normal pregnancy was taken as Gold standard test.
Table-III

Validity tests of CRP as screening tests $(n=150)$

\begin{tabular}{lc}
\hline Validity & CRP \\
Sensitivity & $68.00 \%$ \\
Specificity & $98.00 \%$ \\
Positive Predictive Value & $94.40 \%$ \\
Negative Predictive Value & $86.00 \%$ \\
Positive Likelihood Ratio & 34.00 \\
Negative Likelihood Ratio & 0.33 \\
Diagnostic Accuracy & $88.0 \%$ \\
\hline
\end{tabular}

In study group, CRP values showed significant negative correlation with birth weight. 


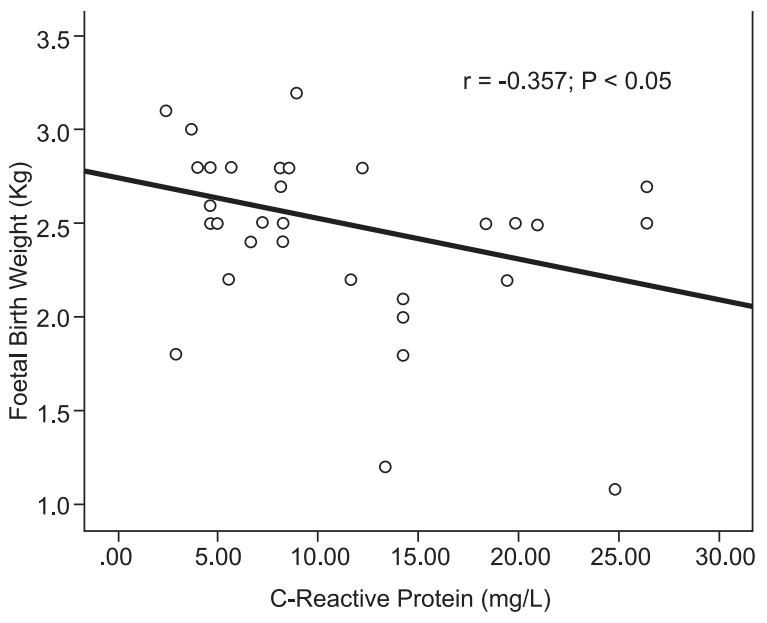

Fig.-1: Relationship between CRP and fetal birth weight in study.

\section{Discussion:}

Preeclampsia (PE) remains one of the most serious complications of pregnancy. According to the World Health Organization, PE is a major cause of both maternal and fetal-neonatal morbidity and mortality ${ }^{14}$ Age range of pre-eclamptic patient are similar in other studies ${ }^{15,16}$ like ours.

The present study was conducted to assess whether CRP level was raised in PE and to reflect its relation with disease progression. In this study mean CRP in study group was $10.48 \pm 6.93 \mathrm{mg} / \mathrm{L}$ and in control group was $3.45 \pm 1.71 \mathrm{mg} / \mathrm{L}$. There is statistically significant difference $(P=0.000)$ in CRP concentration between study and control group. Present study showed that in mild PE cases serum CRP was increased $62.9 \%$ and in severe PE cases it was increased $80 \%$. No significant difference has been observed in serum CRP concentrations between mild and severe PE $(p=0.76)$, though other studies found significant difference of CRP between mild and severe $P E(P=0.001){ }^{17,18}$. Samira $B G$ et al ${ }^{17}$ in a cohort study showed that in first trimester CRP levels were significantly higher among women, who subsequently developed preeclampsia compared with controls $(P$ $=0.000$ ). Different studies showed significantly higher CRP level in pre-eclamptic women than normal pregnant women. ${ }^{19,20}$. In this study we also found high CRP level in preeclamptic women than normal pregnant women.

Regarding validity analysis of different tests in this study $68 \%$ sensitivity and $98 \%$ specificity of CRP were found. Menha $S$ et $a^{21}$, showed $90 \%$ sensitivity and $86.7 \%$ specificity of CRP.
Multiple regression analysis showed that odds ratio of $C R P$ is $104.12(P=0000)$.

Pre-eclamptic patients delivered at a significantly shorter gestational age $(t=2.216, P=0.030)$ that is delivered at an earlier period of gestation as compared to the normotensive women $(P<0.041)^{16,17}$ and same is true for this current study. C-reactive protein (CRP) is a marker of systemic inflammation and synthesis in response to infection and tissue injury and accompanies both acute and chronic inflammatory disorders.

Maternal concentrations of CRP increased in subclinical infection in pregnant women who experience preterm labor and premature rupture of membranes. Presence of elevated levels of CRP during gestation has a link to preeclampsia ${ }^{11,12}$, which is also shown in this study. Hvilsom et al. ${ }^{13}$ reported a significant association of elevated serum CRP levels with a nearly twofold increased risk of delivery before 37 weeks' gestation. Elevated CRP also has a link with intrauterine growth restriction ${ }^{12}$. So there is strong association of increased CRP and premature labour and low birth weight (LBW) baby. CRP is not a cause of premarurity or LBW but it is good predictor of adverse pregnancy outcome like preeclampsia, IUGR and prematurity.

In these series preeclamptic mother delivered low birth weight baby more than normotensive mother. There was significant difference between mean birth weight of study group and that of control group $(2.52 \pm 0.42$ vs $2.88 \pm 0.29 \mathrm{~kg})(P=0.000)$. Luis $B$ et $a l^{19}$, reported a significant difference of birth weight between normal pregnant and preeclamptic mother (3291 \pm 367 vs $2570 \pm 777$ gm respectively $)(P<0.001)$. Another study also showed significant LBW babies in pre-eclamptic women than normal pregnant women $(2.10 \pm 0.38 \mathrm{~kg}$ and $2.86 \pm 0.21 \mathrm{Kg}, p<0.001)$. The fact came out in similar direction as in this series. Multiple regression analysis in study group showed CRP values were inversely correlated with birth weight $(P<0.05)$. It is difficult to predict the severity of preeclampsia clinically. Finding of the present study showed CRP is elevated in women with PE and birth weight is significantly less in this group.

\section{Conclusion:}

Present study showed CRP raised $68 \%$ in study group, whereas it was $2 \%$ in control group. Birth weight was significantly less in case group. Therefore, CRP may be used as cost effective investigation to identify the risk of preeclampsia and its effect on fetal birth weight. 


\section{Acknowledgement:}

We would like to express the gratitude to the participants of the study and special thanks to the authorities of Chittagong Medical College Hospital, Chittagong for permission to carry out the study

\section{References:}

1. Roberts JM. Endothelial dysfunction in preeclampsia. Semin Reprod Endocrinol 1998;16(1):5-15.

2. Judi AT. Severe preeclampsia: Anaesthetic implications of the disease and its management. Am J of Thera 2009; 16:284-288.

3. Report of the National high blood pressure education program working group. Report on high blood pressure in pregnancy. Am J Obstet Gynecol 2000;183:21-22.

4. Mattar F, Sibai BM. Eclampsia VIII: Risk factors for maternal morbidity. Am J Obstet Gynecol 2000; 182:307-312.

5. Lucy CC, Stephen E, Paul S, Annette LB, Lucilla $P$, Andrew HS. Adverse perinatal outcomes and risk factors for preeclampsia in women with chronic Hypertension. AHA2008; 51: 1002-1009.

6. ACOG committee on Obstetric practice. ACOG practice bulletin. Diagnosis and management of preeclampsia and eclampsia. Obstetricians and Gynecologists. Int J Gynaecol Obstet 2002; 77:67-75.

7. Shamsuddin L, Rouf S, Khatun H. Perinatal outcome of eclampsia patients. Bangladesh J Obstet Gynecol 1995;10(2):67-72.

8. Saito S, Shiozaki A, Naka Shima A, Sakai M, Sasaki Y. The role of the immune system in preeclampsia. Mol Aspects Med 2007;28: 192-209.

9. Qiu C, Luthy DA, Zhang C, Walsh SW, Leisenring WM, Williams MA. A Prospective study of maternal serum C-reactive protein concentrations and risk of preeclampsia. Am J Hypertension 2004; 17:154-160.

10. Ertas I, Kahyaoglu S, Yilmaz B, Ozel M, Sut N, Guven $\mathrm{M}$ et al. Association of maternal serum high sensitivity C-reactive protein level with body mass index and severity of preeclampsia at third trimester. J Obstet Gynecol Res. 2010;36: 970-977.
11. Wolf M, Kettyle E, Sandler L, et al. Obesity and preeclampsia: the potential role of inflammation. Obstet Gynecol 2001;98:757-62.

12. Tjoa ML, van Vugt JM, Go AT, et al. Elevated Creactive protein levels during first trimester of pregnancy are indicative of preeclampsia and intrauterine growth restriction. J Reprod Immunol 2003;59:29-37.

13. Hvilsom GB, Thorsen P, Jeune B, et al. C-reactive protein: a serological marker for preterm delivery? Acta Obstet Gynecol Scand 2002;81:424-9.

14. Ilhan $N$, Simsek $M$. The changes of trace elements, malondialdehyde levels and superoxide dismutase activities in pregnancy with or without preeclampsia. Clin Biochem 2002;35:393-397.

15. Paternoster DM, Fantinato S, Stella A, Narhorrgue KN, Milani M, Plebani M et al. Creactive protein in hypertensive disorders in pregnancy. Clinical and Applied haemostasis 2006;12(3):330-337.

16. Kishwara S, Tanira S, Omar E, Waed F, Ara S. Effect of Preeclampsia on Perinatal Outcome A study done in Specialized Urban Hospital Setup in Bangladesh. BMJ 2011;40 (1):33-36.

17. Samira BG, Lida MB, Narges AM, Bita M, Mohamad A. Association of high-sensitivity Creactive protein serum levels in early pregnancy with the severity of preeclampsia and fetal birth weight. J Perinat Med 2012;40:601-605.

18. Siddiqua SF. Serum C-reactive protein in preeclampsia and its effect on fetal outcome [Thesis]. Dhaka: Bangabandhu Sheikh Mujib Medical University; 2007.

19. Luis B, Alice SS, Muricel C, Josephine C, Alexandre $Q$, Inene $R$ et al. Neutrophil activation and $\mathrm{C}$-reactive protein concentration in preeclampsia. Hypertension in preg 2003;22: 129-141.

20. Sawsan KS. Correlation of matrenal C-reactive protein and serum fibrinogen with the severity of preeclampsia. Kufa Med. Journal 2012;15(1): 346-353.

21. Menha S, Nervana S, Susan AW, Mohamed SI. Emerging role of endothelial and inflammatory markers in PE. Disease markers 2009;26: 127-133. 